\title{
Economic Order Quality Model for Determining the Sales Prices of Fresh Goods at Various Points in Time
}

\author{
Po-Yu Chen \\ Department of Advertising and Strategic Marketing, Ming Chuan University, No. 250 Zhong Shan N. Rd., Sec. 5, Taipei, Taiwan \\ Correspondence should be addressed to Po-Yu Chen; chenboy@mail.mcu.edu.tw
}

Received 13 January 2017; Revised 13 July 2017; Accepted 2 August 2017; Published 10 September 2017

Academic Editor: Yong He

Copyright (C) 2017 Po-Yu Chen. This is an open access article distributed under the Creative Commons Attribution License, which permits unrestricted use, distribution, and reproduction in any medium, provided the original work is properly cited.

\begin{abstract}
Although the safe consumption of goods such as food products, medicine, and vaccines is related to their freshness, consumers frequently understand less than suppliers about the freshness of goods when they purchase them. Because of this lack of information, apart from sales prices, consumers refer only to the manufacturing and expiration dates when deciding whether to purchase and how many of these goods to buy. If dealers could determine the sales price at each point in time and customers' intention to buy goods of varying freshness, then dealers could set an optimal inventory cycle and allocate a weekly sales price for each point in time, thereby maximizing the profit per unit time. Therefore, in this study, an economic order quality model was established to enable discussion of the optimal control of sales prices. The technique for identifying the optimal solution for the model was determined, the characteristics of the optimal solution were demonstrated, and the implications of the solution's sensitivity analysis were explained.
\end{abstract}

\section{Introduction}

Previous studies have demonstrated the relevance of food freshness and consumer utility. Although consumers judge food freshness through the senses [1-4] and through labels containing information on the manufacture and expiration date, the freshness information available to consumers remains asymmetrical. This asymmetry usually originates from how retailers perform (1) fresh food replenishment and (2) relabeling. When retailers replenish their goods, their shelves contain the same goods with differing expiration dates, and the retailers' clever arrangement and stacking of the goods render consumers more likely to access those with closer expiration dates. In practice, retailers offer discounts on fresh goods with closer expiration dates, thus requiring the goods to be relabeled. Many supermarkets employ fixed percentage labeling (such as $20 \%$ discounts) to affect consumers' purchase behaviors. However, the relabeling of fresh goods may involve human error factors (even tampering with expiration dates). Therefore, numerous supermarkets in Europe, the United States, and Japan employ label management models containing expiration dates based on the label dates and solar dates, although this also leads to freshness information gaps between consumers and retailers. In addition, some chain retailers adopt the same price discounts for expiring fresh goods (e.g., Taiwan's PX Mart supermarket chain offering $20 \%$ discounts for expiring fresh goods) while overlooking various factors relating to consumers' demands for goods with differing expiration dates (degree of freshness). This practice is clearly inappropriate. Such neglect has a significant impact on consumers' price discrimination and retailers' expected profits $[5,6]$. If dealers can determine the sales price at each point in time and customers' intention to buy food of varying freshness, then dealers can set an optimal inventory cycle and allocate a weekly sales price for each point in time, thereby maximizing the profit per unit time.

The research frameworks for studying the inventory optimization problems of fresh (or perishable) goods tend to be highly complex because the freshness of goods affects consumer utility and thus their demands. The earliest literature review on the inventory model for deteriorating items was a review of inventory models for perishable goods conducted by Nahmias [7], which was expanded by Goyala and Giri [8]. Literature reviews published from 2011 to 2016 have treated 
fresh (or perishable) goods as a distinct classification and examined relevant research. For detailed literature reviews on the inventory model for deteriorating items, see Nahmias [9], Karaesmen et al. [10], Bakker et al. [11], and Janssen et al. [12]. This study avoided repeating these previous works and instead focused on a deeper exploration of the problems involved in fresh goods inventories.

The traditional economic order quantity (EOQ) model was designed to solve the problem encountered by buy-in and sell-out dealers, who determine the inventory standard of goods at the beginning of each period in response to the given demand rate of goods, thereby minimizing the cost per unit time. To expand the applications of the conventional EOQ model, various types of extended inventory models have been developed by inventory management scholars in recent years in their studies on fresh (or perishable) goods inventories. According to loosened assumptions, these extended models (some of which can be categorized as hybrid models comprising more than one type) can be divided into the following types.

Type 1. The assumption of the traditional EOQ model has been relaxed from "the demand rate is a given constant" to "the demand rate varies according to time" [13-32].

Type 2. The assumption of the traditional EOQ model has been changed from "goods are nondegenerative" to "goods are degenerative goods (e.g., petroleum and other volatile products) that decrease in volume over time even when unsold" [33-36]. Since 2010, an increasing number of studies on deteriorating goods inventory have focused on fresh (perishable) goods whose quality deteriorates over time [25, 37-48].

Type 3. The assumption of the traditional EOQ model has been changed from "the unit prices of the goods acquired (purchased) by dealers are a fixed constant" to "unit prices may be affected by lot size owing to volume discounts" [14, 49-56].

Type 4. The assumption of the traditional EOQ model has been relaxed from "sales prices are a given constant (fixed demand rate)" to "sales prices are a decision variable for dealers" $[25,38,50,57-73]$.

Numerous inventory models for fresh (or perishable) goods have been proposed in the past 20 years, with pricing problems being one of the most extensively researched topics in the past 10 years. Most research on pricing problems has concentrated on discount optimization; only a few scholars have specifically studied dynamic price optimization, and most of which studies have been conducted in the past 56 years [25, 38, 67-73]. In this study, goods dealers were assumed to possess the opportunity and capability to determine sales prices at each point in time (sales prices are the decision variable for goods dealers). This assumption supports the Type 4 EOQ model, which posits that dealers may decide the sales prices at each point in time, in comparison to the traditional model that states dealers may determine only one sales price standard.

\section{Mathematical Model}

\subsection{Parameters}

$e$ : time at which goods expire. Specifically, $e$ represents the duration from the time of goods purchase $(t=0)$ to the time of their expiration.

$h$ : storage cost of a unit of goods within a unit time.

$c$ : purchase price of a unit of goods.

A: setup cost.

\subsection{Given Functions}

$d=d(p(t))$ : the potential demand rate for goods as reflected by customer reaction to the sales price $p$, where $d(p(t))>0$. A potential demand rate indicates the demand rate for goods when customers became aware of the sales price $p(t)$ at the point in time $t$ but are not aware of or have not considered the expiration time $e$. In this study, a linear function of the sales price $p(t)$ at the point in time $t$ was established as follows:

$$
d(p(t))=a-b p(t), \quad p(t) \in\left[0, \frac{a}{b}\right] .
$$

$a$ : maximal limit of the potential demand rate, where $a>0$.

$a / b$ : maximal limit of $p(t)$. This means that, at the point of time $t$,

when $p(t)$ decreases to zero, $d(p(t))$ increases to $a$

when $p(t)$ increases to $\frac{a}{b}, d(p(t))$ decreases to zero.

$r=r(t)$ : the intentions of consumers to purchase goods when consumers enter the place of sale at point in time $t$, learn about the sales price $p(t)$, become potential demanders for the goods, and find that the remaining time until the goods' expiration is $(e-t)$. In particular, $r(t) \in[0,1]$ is the linear decreasing function of $t, t \in[0, e)$, and satisfies $r(0)=1$ and $r(t)=0, \forall t \geq e$.

Thus

$$
r(t)= \begin{cases}\frac{e-t}{e}, & \text { when } t \in[0, e) \\ 0, & \text { when } t \geq e\end{cases}
$$

\subsection{Decision Variables}

$p=p(t)$ : sales price at the point in time $t$, where $p(t) \in[0, a / b], \forall t$.

$x=x(t)$ : inventory standard at $t$, where $x(t)$ is the decreasing function of $t$ in the inventory period $\left[0, T_{x}\right]$ corresponding to $x$, and $x\left(T_{x}\right)=0$. 
$T_{x}$ : duration of the inventory cycle corresponding to the dealer decision variable $x$. Because $e$ represents the expiration time of the goods, $T_{x}$ corresponding to the target function $x$ must fulfill the following inequality:

$$
T_{x} \leq e
$$

$L_{x}$ : per unit time profit of the dealer's decision variable $x$ corresponding to the inventory cycle $T_{x}$; that is,

$L_{x}$

$=\frac{1}{T_{x}}\left[\right.$ dealer's profit within one inventory cycle $\left.T_{x}\right]$.

$-x^{\prime}(t)$ : sales rate of the goods corresponding to $x$ at the point in time $t$.
From (1) and (3), the following is obtained:

$$
-x^{\prime}(t)=d(p(t)) \cdot r(t)=(a-b p(t)) \cdot \frac{e-t}{e} .
$$

Because $p(t) \in[0, a / b]$, the following can be obtained from the preceding equation:

$$
\frac{-x^{\prime}(t) e}{e-t}=a-b p(t) \in[0, a], \quad \forall t \in\left[0, T_{x}\right]
$$

From (7), the following can be obtained:

$$
p(t)=\frac{e x^{\prime}(t)}{b(e-t)}+\frac{a}{b}, \quad t \in\left[0, T_{x}\right] \leq[0, e] .
$$

Through (7) and (8), the mathematical model that dealers can use to determine the decision variable $x$ to maximize the profit per unit time corresponding to $x$ is established as follows:

$$
\begin{array}{ll}
\max _{x} & L(x)=\frac{1}{T_{x}}\left\{\left[\int_{0}^{T_{x}}\left(\frac{e x^{\prime}(t)}{b(e-t)}+\frac{a}{b}\right)\left(-x^{\prime}(t)\right)-h x(t)\right] d t-c x(0)-A\right\} . \\
\text { s.t. } \quad x^{\prime}(t) \text { exists as the continuous function of }\left[0, T_{x}\right] ; \\
\\
\quad \frac{-x^{\prime}(t) e}{e-t} \in[0, a], \quad \forall t \in\left[0, T_{x}\right] ; x\left(T_{x}\right)=0 ; x(0) \text { exhibits freedom }
\end{array}
$$

(that is $x(0)$ varies according to the feasible solution $x$ )

\section{Optimal Solution of Model (9)}

Assume $x^{*}=x^{*}(t), t \in\left[0, T_{x^{*}}\right]$ is the optimal solution of (9). The required conditions of $x$ are obtained in the following procedures.

$T_{x}$ corresponding to the feasible solution $x=x(t)$ in (9) must fulfill the following inequality:

$$
p\left(T_{x}\right)-\left(c+T_{x} h\right) \geq 0 .
$$

If $\left[p\left(T_{x}\right)-\left(c+T_{x} h\right)\right]<0$, then dealers can reduce the initial amount of purchase at $t=0$ and shorten the inventory cycle $T_{x}$, thereby maximizing the profit.
Because the objective function of (10) is exceptional (the integral value must be divided by $T_{x}$ ) and the feasible solution must fulfill the constraint that $-x^{\prime}(t) e /(e-t) \epsilon$ $[0, a], \forall t \in\left[0, T_{x}\right],(9)$ becomes a nonstandard calculus of variation problem. Identifying the conditions required for the optimal solution to this problem is the focus of this section.

To solve (9), it was divided into two problems, namely, (11) and (13). Given the $T$ value, let $\bar{x}_{T}(t)$ be the optimal solution of (11) and $L_{T}$ the target value of the optimal solution; that is,

$$
\begin{aligned}
L_{T}=\max _{x} & \frac{1}{T}\left\{\left[\int_{0}^{T}\left(\frac{e x^{\prime}(t)}{b(e-t)}+\frac{a}{b}\right)\left(-x^{\prime}(t)\right)-h x(t)\right] d t-c x(0)-A\right\} \\
\text { s.t. } \quad & x^{\prime}(t) \text { exists as the continuous function of }[0, T] ; \\
& \frac{-x^{\prime}(t) e}{e-t} \in[0, a], \forall t \in[0, T] ; x(T)=0 ; x(0) \text { exhibits freedom; }
\end{aligned}
$$

and $T$ value is given. 
Let $\bar{x}_{T}(t)$ be the optimal solution of (11); the difference between (9) and (11) is as follows: the period of a cycle in the feasible solutions $x$ to problem (11) equals the given $T$ value, and the function $\bar{x}_{T}(t)$ and target value $L_{T}$ of the optimal solution vary according to the given $T$ value. If the given $T$ value in (11) is applied as the period $T^{*}$ of the function $x^{*}(t)$ of the optimal solution to (9) (let $T=T^{*}$, and substitute it into (11)), as seen, the optimal solution of (9) will also be the optimal solution of (11); that is,

$$
\bar{x}_{T^{*}}(t)=x^{*}(t), \quad \forall t \in\left[0, T^{*}\right] .
$$

Compared with (9) and (11), (12) can be employed to obtain $T$ as the optimal solution to (13):

$$
L_{T^{*}}=\max _{T} L_{T}
$$

because (11) involves the constraint $-x^{\prime}(t) e /(e-t) \quad \epsilon$ $[0, a], \forall t \in\left[0, T_{x}\right]$, such that (11) is still a nonstandard calculus of variation problem. Therefore, this constraint was neglected temporarily, and the following standard calculus of variation problem (14) was considered.

$$
\begin{aligned}
L_{T}=\max _{x} & \frac{1}{T}\left\{\left[\int_{0}^{T}\left(\frac{e x^{\prime}(t)}{b(e-t)}+\frac{a}{b}\right)\left(-x^{\prime}(t)\right)-h x(t)\right] d t-c x(0)-A\right\} \\
\text { s.t. } & x^{\prime}(t) \text { exists as the continuous function of }\left[0, T_{x}\right] ; x(T)=0 ; \\
& x(0) \text { exhibits freedom, and the } T \text { value is given. }
\end{aligned}
$$

Applying the existing theory of calculus of variations to this type of problem [74] yields the optimal solution to (14) labeled as $\widehat{x}_{T}(t)$. The following conditions must be fulfilled.

The condition of the Euler equation:

$$
-h=\frac{d}{d t}\left[\frac{-2 e}{b-(e-t)} \cdot \widehat{x}_{T}(t)-\frac{a}{b}\right] .
$$

The condition of $x(0)$ as a target salvage value:

$$
\frac{-2}{b} \cdot \widehat{x}_{T}^{\prime}(0)-\frac{a}{b}+c=0, \quad \forall t \in[0, T] .
$$

Integrating $t$ with (15) and using (16) yield the following formula:

$$
h t+c=\frac{2 e}{b(e-t)} \cdot \hat{x}_{T}^{\prime}(t)+\frac{a}{b}, \quad \forall t \in[0, T] .
$$

Using (2), (10), and (17), the following is obtained:

$$
\begin{aligned}
\frac{-\widehat{x}_{T}^{\prime}(t) \cdot e}{e-t} & =\frac{b}{2}\left(\frac{a}{b}-c-h t\right) \in[0, a], \quad \forall t \in[0, T] . \\
\widehat{x}_{T}^{\prime \prime}(t) & =\frac{b}{2 e}\left[\frac{a}{b}-c-h t+(e-t) h\right] \geq 0 .
\end{aligned}
$$

Because the set of feasible solutions for (14) includes those for (11), the feasible solutions $x$ for (11) are also feasible solutions for (14). However, the feasible solutions for (14) may not necessarily be those for (11). Therefore, the optimal solution $\widehat{x}_{T}$ to (18) has been verified to also be the optimal solution $\widehat{x}_{T}$ to (11).

Integrating (17) and using $x_{T}(T)=0$ yield the following:

$$
\begin{aligned}
\bar{x}_{T}(t) & =\widehat{x}_{T}(t) \\
= & \frac{-b}{2 e}\left[\left(\frac{a}{b}-c\right) e t-\left(\frac{a}{b}-c+h e\right) \frac{t^{2}}{2}+h \frac{t^{3}}{3}\right]
\end{aligned}
$$

$$
\begin{array}{r}
+\frac{b}{2 e}\left[\frac{a}{b}(-c) e T-\left(\frac{a}{b}-c+h e\right) \frac{T^{2}}{2}+h \frac{t^{3}}{3}\right], \\
\forall t \in[0, T] .
\end{array}
$$

By partial integration,

$$
\begin{gathered}
\int_{0}^{T}-h \bar{x}_{T}(t) d t \text { is written as } \int_{0}^{T} h t \bar{x}_{T}^{\prime}(t) d t ; \\
-c x(0) \text { is written as } \int_{0}^{T} \bar{x}_{T}^{\prime}(t) d t .
\end{gathered}
$$

Using (21) and applying (19) into the objective function (11) yield the following:

$$
\begin{aligned}
L_{T} & =\frac{1}{T} \int_{0}^{T}\left[\left(\frac{e \bar{x}_{T}^{\prime}(t)}{b(e-t)}+\frac{a}{b}\right)\left(-{\overline{x^{\prime}}}_{T}(t)\right)-h x(t)\right] d t \\
& -c x(0)-A \\
& =\frac{1}{T}\left[\int_{0}^{T}\left(\frac{e \bar{x}_{T}^{\prime}(t)}{b(e-t)}+\frac{a}{b}-c-h t\right)\left(-\bar{x}_{T}^{\prime}(t)\right) d t\right. \\
& -A] ; \quad \text { using }(17) \\
= & \frac{1}{T}\left[\int_{0}^{T}\left(\frac{h t+c-a / b}{2}+\frac{a}{b}-c-h t\right)\right. \\
& \left.\frac{b(e-t)}{2 e}\left(\frac{a}{b}-c-h t\right) d t-A\right] \\
= & \frac{1}{T}\left[\int_{0}^{T} \frac{b}{4 e}(e-t)\left(\frac{a}{b}-c-h t\right)^{2} d t-A\right] .
\end{aligned}
$$




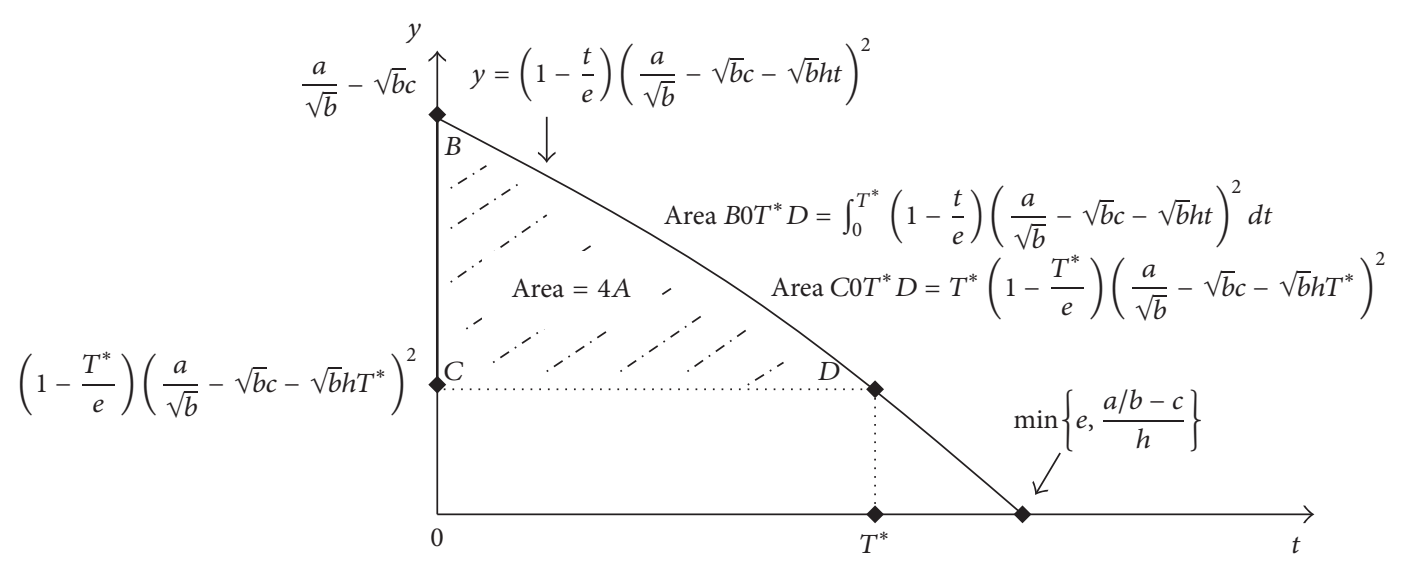

FIgURE 1: The optimal inventory cycle $T^{*}$.

From (22), the optimal solution $T^{*}$ to (13) is acquired. The following conditions must be satisfied (see Appendix A for details):

$$
\begin{aligned}
0 & =\left.\frac{d}{d_{T}} L_{T}\right|_{T^{*}}=\frac{b}{4 e T^{*}}\left(e-T^{*}\right)\left(\frac{a}{b}-c-h T^{*}\right)^{2} \\
& -\frac{1}{T^{* 2}}\left[\int_{0}^{T^{*}} \frac{b}{4 e}(e-t) \times\left(\frac{a}{b}-c-h t\right)^{2} d t-A\right] \\
& =\frac{1}{4 T^{* 2}}\left[T^{*}\left(1-\frac{T^{*}}{e}\right)\right. \\
& \cdot\left(\frac{a}{\sqrt{b}}-\sqrt{b} \cdot c-\sqrt{b} \cdot h T^{*}\right)^{2}-\int_{0}^{T^{*}}\left(1-\frac{t}{e}\right) \\
& \left.\times\left(\frac{a}{\sqrt{b}}-\sqrt{b} \cdot c-\sqrt{b} \cdot h t\right)^{2} d t+4 A\right], \\
\frac{d^{2}}{d_{T^{2}}} & L_{T}=\frac{b}{4 e T^{* 2}}\left[\left(e-2 T^{*}\right)\left(\frac{a}{b}-c-h T^{*}\right)^{2}\right. \\
& +T^{*}\left(e-T^{*}\right) \times(-2 h)\left(\frac{a}{b}-c-h T^{*}\right)^{2}-\left(e-T^{*}\right) \\
& \left.\cdot\left(\frac{a}{b}-c-h T^{*}\right)^{2}\right]=\frac{-b}{4 e T^{* 2}} T^{*}\left(\frac{a}{b}-c-h T^{*}\right) \\
& \cdot\left[\left(\frac{a}{b}-c-h T^{*}\right)+2 h\left(e-T^{*}\right)\right]
\end{aligned}
$$$$
\leq 0 \text {. }
$$

As (2) and (10) reveal, $a / b-c-h T^{*} \geq 0$; (4) indicates that $e-T^{*} \geq 0$. Therefore, (24) confirms that

$$
\left.\frac{d^{2}}{d_{T^{2}}} L_{T}\right|_{T^{*}} \leq 0 .
$$

This process indicates the following.

$T^{*}$ satisfying the first-order conditions of the optimal solutions in (23) must also satisfy the second-order conditions of the optimal solutions in (25).
Figure 1 depicts $T^{*}$ for (23).

Next, (12), (18), and (20) can be used to obtain the optimal solution $x^{*}$ of (9):

$$
\begin{aligned}
& x^{*}(t)=\frac{b}{2 e}\left[\left(\frac{a}{b}-c\right) \cdot e\left(T^{*}-t\right)\right. \\
& \left.-\left(\frac{a}{b}-c+h e\right) \frac{T^{* 2}-t^{2}}{2}+h \cdot \frac{T^{* 3}-t^{3}}{3}\right], \\
& t \in\left[0, T^{*}\right] \\
& x^{* \prime}(t)=\frac{-b}{2 e}(e-t)\left(\frac{a}{b}-c-h t\right), \quad t \in\left[0, T^{*}\right] .
\end{aligned}
$$

From (27) and (8), the optimal price $p^{*}(t)$ can be obtained:

$$
p^{*}(t)=\frac{1}{2}\left(\frac{a}{b}+c+h t\right), \quad t \in\left[0, T^{*}\right]
$$

Problem (28) indicates that the initial optimal sales price for a favorable $p^{*}(0)$ is $(1 / 2)(a / b+c)$; the initial unit profit, $p^{*}(0)-$ $c$, is $(1 / 2)(a / b-c)$.

Problem (26) reveals that if changes in some of the parameters cause $T^{*}$ and $x^{*}(0)$ to change, then the rate of change for these two parameters is expressed as follows:

$$
\begin{aligned}
& \frac{d x^{*}(0)}{d_{T^{*}}} \\
& =\frac{b h}{2 e}\left[T^{* 2}+\left(\frac{a / b-c}{h}+e\right) T^{*}+\frac{a / b-c}{h} \cdot e\right] \\
& =\frac{b h}{2 e}\left(T^{*}-\frac{a / b-c}{h}\right)\left(T^{*}-e\right)=-x^{* \prime}\left(T^{*}\right)>0 .
\end{aligned}
$$

This function illustrates that the rate of change of the initial inventory standard $x^{*}(0)$ at the beginning of the inventory cycle of the goods to the optimal inventory period $T^{*}$ is equal to the sales rate of the goods at the end of the inventory cycle $-x^{*}(T)$. 


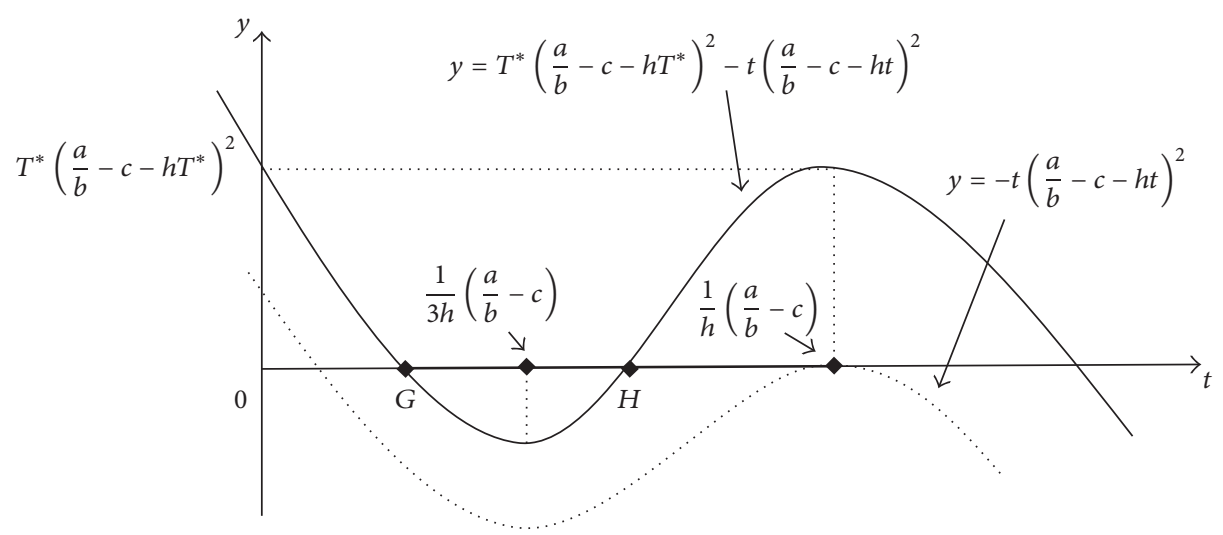

Figure 2: Effect of the increase in $e$ on $T^{*}$.

\section{Sensitivity Analysis of the Optimal Solution $x^{*}=x^{*}(t)$}

If the sensitivity analysis result of $T^{*}$ from (26), (27), and (28) is obtained, then the sensitivity analysis result of the optimal inventory function, $x^{*}(t)$, and the optimal sales price function, $p^{*}(t)$, can be acquired.

4.1. Effect of Changes in A on $T^{*}$. As shown in Figure 1, when $A$ increases, the area of $B C D$ increases, and the curves in the figure remain unchanged. Thus, $T^{*}$ increases. Therefore,

$$
\frac{\partial T^{*}}{\partial A}>0
$$

However, $T^{*}$ is labeled as $T^{*}(A)$ because it varies according to $A$ in (24). Partially differentiating $A$ with (24) yields the following formula:

$$
\begin{aligned}
& \frac{\partial T^{*}}{\partial A}=4 T^{*-1}\left[\left(\frac{a}{\sqrt{b}}-\sqrt{b} c-\sqrt{b} h T^{*}\right)^{2} \cdot \frac{1}{e}\right. \\
& \left.\quad+\left(1-\frac{T^{*}}{e}\right) \times 2\left(\frac{a}{\sqrt{b}}-\sqrt{b} c-\sqrt{b} h T^{*}\right) \sqrt{b} h\right]^{-1} \\
& \quad>0 .
\end{aligned}
$$

4.2. Effect of Changes in e on $T^{*}$. Partially differentiating $e$ with (23) yields the following formula (see Appendix B for details):

$$
\begin{aligned}
& \frac{\partial T^{*}}{\partial e}=T^{* \prime}(e) \\
& =\frac{1 / e \int_{0}^{T^{*}}\left[T^{*}\left(a / b-c-h T^{*}\right)^{2}-t(a / b-c-h t)^{2}\right] d t}{T^{*}\left(a / b-c-h T^{*}\right)\left[\left(a / b-c-h T^{*}\right)+2 h\left(e-T^{*}\right)\right]} \\
& =\frac{1}{12}\left(\frac{a}{b}-c-h T^{*}\right)^{2}\left(6 T^{*}+\frac{a / b-c-h T^{*}}{h}\right) \\
& \times\left(2 T^{*}-\frac{a / b-c-h T^{*}}{h}\right)+\frac{(a / b-c)^{4}}{12 h^{2}} .
\end{aligned}
$$

The incorporation of (32) and (33) verifies that $\partial T^{*} / \partial e>$ 0 . In Scenario (1), assume that $T^{*}$ is shown at the $G$ point in Figure 2. The numerator of (32) is larger than zero; therefore, $\partial T^{*} / \partial e>0$. In Scenario (2), assume that $T^{*}$ is shown at the $H$ point in Figure 2. Then, (33) reveals that $\partial T^{*} / \partial e>0$.

$$
T^{* \prime}(h)=\frac{-2 \int_{0}^{T^{*}}\left[T^{*}\left(e-T^{*}\right)\left(a / b-c-h T^{*}\right)-t(e-t)(a / b-c-h t)\right] d t}{T^{*}\left(a / b-c-h T^{*}\right)^{2}+2 T^{*}\left(e-T^{*}\right)\left(a / b-c-h T^{*}\right)}>0 .
$$

4.4. Effect of Changes in $c$ on $T^{*}$. Partially differentiating $c$ with (23) yields the following formula (see Appendix D for details):

$$
T^{* \prime}(c)=\frac{-2 \int_{0}^{T^{*}}\left[T^{*}\left(e-T^{*}\right)\left(a / b-c-h T^{*}\right)-(e-t)(a / b-c-h t)\right] d t}{2 h T^{*}\left(e-T^{*}\right)\left(a / b-c-h T^{*}\right)+T^{*}\left(a / b-c-h T^{*}\right)^{2}}
$$




\section{Conclusions}

This study divided the inventory promotion model of fresh goods into four categories and examined published academic journals papers that have investigated these categories, finding that few scholars have studied the dynamic pricing of fresh goods. The EOQ model established in this study enables dealers to determine sales prices at each point in time after the relationship between consumer reactions to the freshness of the goods and purchasing intentions is determined.

The optimal inventory cycle $T^{*}$ can be obtained from (23), and the implication of $T^{*}$ is illustrated in Figure 1. Within the optimal inventory cycle $\left[0, T^{*}\right]$, the optimal inventory standard $x^{*}(t)$ at $t$ is expressed in (26), the optimal sales rate $-x^{* \prime}(t)$ at $t$ is expressed in (27), and the optimal sales price $p^{*}(t)$ at $t$ is expressed in (28).

We also analyzed the sensitivity of the optimal solution to changes in each variable. The results revealed the following. (a) The optimal inventory cycle $T^{*}$ and the initial inventory standard $x^{*}(0)$ both increased as the setup cost $A$ increased; the rate of change is displayed in (31) and (29). (b) $T^{*}$ and $x^{*}(0)$ both increased as the expiration time of the goods $e$ increased; the rate of change is shown in (32) and (29). (c) $T^{*}$ and $x^{*}(0)$ both decreased as the inventory cost $h$ increased; the rate of change is illustrated in (34) and (29). (d) $T^{*}$ and $x^{*}(0)$ both increased as the unit purchase price $c$ increased; the rate of change is depicted in (35) and (29).

The main contribution of this research model to management is the incorporation of consumers' demand response to the manufacture and expiration dates (or degree of freshness) of fresh goods. Retailers tend to have both old and new goods on their shelves when replenishing fresh goods-that is, they stock same goods with differing expiration dates. They may even have differing expiration dates despite having the same manufacture dates because of environmental factors such as transportation and storage. Therefore, retailers can set the prices at different time points of the goods' shelf life instead of adopting a straightforward price discount as in the past, which may cause them to lose part of their expected profits. Using the parameters to determine the rate of change for the optimal solution can assist fresh goods retailers in conducting immediate price control.

\section{Appendix}

\section{A. The Necessary Condition for the Optimal Solution $T^{*}$}

From (22), the optimal solution $T^{*}$ to (13) is acquired. The following conditions must be satisfied:

$$
\begin{aligned}
0 & =\left.\frac{d}{d_{T}} L_{T}\right|_{T^{*}}=\frac{b}{4 e T^{*}}\left(e-T^{*}\right)\left(\frac{a}{b}-c-h T^{*}\right)^{2} \\
& -\frac{1}{T^{* 2}}\left[\int_{0}^{T^{*}} \frac{b}{4 e}(e-t) \times\left(\frac{a}{b}-c-h t\right)^{2} d t-A\right] \\
& =\frac{b}{4 e T^{* 2}}\left[T^{*}\left(e-T^{*}\right)\left(\frac{a}{b}-c-h T^{*}\right)^{2}\right.
\end{aligned}
$$

$$
\begin{aligned}
& \left.-\int_{0}^{T^{*}}(e-t) \times\left(\frac{a}{b}-c-h t\right)^{2} d t+\frac{4 e A}{b}\right] \\
& =\frac{1}{4 T^{* 2}}\left[T^{*}\left(1-\frac{T^{*}}{e}\right)\right. \\
& \cdot\left(\frac{a}{\sqrt{b}}-\sqrt{b} \cdot c-\sqrt{b} \cdot h T^{*}\right)^{2} \\
& -\int_{0}^{T^{*}}\left(1-\frac{t}{e}\right) \times\left(\frac{a}{\sqrt{b}}-\sqrt{b} \cdot c-\sqrt{b} \cdot h t\right)^{2} d t \\
& +4 A]
\end{aligned}
$$

$$
\begin{aligned}
& \left.\frac{d^{2}}{d_{T^{2}}} L_{T}\right|_{T^{*}}=\frac{b}{4 e T^{* 2}}\left[\left(e-2 T^{*}\right)\left(\frac{a}{b}-c-h T^{*}\right)^{2}\right. \\
& +T^{*}\left(e-T^{*}\right) \times(-2 h)\left(\frac{a}{b}-c-h T^{*}\right)^{2} \\
& \left.-\left(e-T^{*}\right)\left(\frac{a}{b}-c-h T^{*}\right)^{2}\right]=\frac{-b}{4 e T^{* 2}} T^{*}\left(\frac{a}{b}-c\right. \\
& \left.-h T^{*}\right)\left[\left(\frac{a}{b}-c-h T^{*}\right)+\left(e-T^{*}\right) \cdot 2 h\right] \\
& =\frac{-b}{4 e T^{* 2}} T^{*}\left(\frac{a}{b}-c-h T^{*}\right)\left(\frac{a}{b}-c+2 e h\right. \\
& \left.-3 h T^{*}\right)=\frac{-b}{4 e T^{* 2}} T^{*}\left(\frac{a}{b}-c-h T^{*}\right) \\
& .\left[\left(\frac{a}{b}-c-h T^{*}\right)+2 h\left(e-T^{*}\right)\right]
\end{aligned}
$$

$\leq 0$.

\section{B. Derivation Process of $T^{* \prime}(e)$ in Section 4.2}

In (23), because $T^{*}$ varies according to $e, T^{*}$ is labeled as $T^{*}(e)$. Partially differentiating $e$ with (23) yields the following formula:

$$
\begin{aligned}
0= & T^{*}\left(1-T^{* \prime}(e)\right)\left(\frac{a}{b}-c-h T^{*}\right)^{2}+\left(e-T^{*}\right) \\
& \cdot T^{* \prime}(e) \\
& \cdot\left[\left(\frac{a}{b}-c-h T^{*}\right)^{2}-2 h T^{*}\left(\frac{a}{b}-c-h T^{*}\right)\right] \\
& -\left(e-T^{*}\right)\left(\frac{a}{b}-c-h T^{*}\right)^{2} T^{* \prime}(e) \\
& -\int_{0}^{T^{*}}\left(\frac{a}{b}-c-h t\right)^{2} d t+\frac{4 A}{b}, \quad \forall e .
\end{aligned}
$$


Thus

$$
\begin{aligned}
\frac{\partial T^{*}}{\partial e}= & T^{* \prime}(e)=\frac{4 A / b-\int_{0}^{T^{*}}\left[(a / b-c-h t)^{2}-\left(a / b-c-h T^{*}\right)^{2}\right] d t}{T^{*}\left(a / b-c-h T^{*}\right)\left[\left(a / b-c-h T^{*}\right)+2 h\left(e-T^{*}\right)\right]} ; \text { using }(23) \\
= & \frac{\int_{0}^{T^{*}}\left[(1-t / e)(a / b-c-h t)^{2}-\left(1-T^{*} / e\right)\left(a / b-c-h T^{*}\right)^{2}\right] d t}{T^{*}\left(a / b-c-h T^{*}\right)\left[\left(a / b-c-h T^{*}\right)+2 h\left(e-T^{*}\right)\right]} \\
& -\frac{\int_{0}^{T^{*}}\left[(a / b-c-h t)^{2}-\left(a / b-c-h T^{*}\right)^{2}\right] d t}{T^{*}\left(a / b-c-h T^{*}\right)\left[\left(a / b-c-h T^{*}\right)+2 h\left(e-T^{*}\right)\right]}=\frac{(1 / e) \int_{0}^{T^{*}}\left[T^{*}\left(a / b-c-h T^{*}\right)^{2}-t(a / b-c-h t)^{2}\right] d t}{T^{*}\left(a / b-c-h T^{*}\right)\left[\left(a / b-c-h T^{*}\right)+2 h\left(e-T^{*}\right)\right]} \\
= & \frac{T^{* 2}\left(a / b-c-h T^{*}\right)^{2}}{e T^{*}\left(a / b-c-h T^{*}\right)\left[\left(a / b-c-h T^{*}\right)+2 h\left(e-T^{*}\right)\right]} \\
& -\frac{\left[(1 / 3 h)\left(a / b-c-h T^{*}\right)^{3}-\left(1 / 12 h^{2}\right)(a / b-c)^{4}+\left(1 / 12 h^{2}\right)\left(a / b-c-h T^{*}\right)^{4}\right]}{e T^{*}\left(a / b-c-h T^{*}\right)\left[\left(a / b-c-h T^{*}\right)+2 h\left(e-T^{*}\right)\right]} \\
= & \frac{1}{12}\left(\frac{a}{b}-c-h T^{*}\right)^{2}\left(6 T^{*}+\frac{a / b-c-h T^{*}}{h}\right) \times\left(2 T^{*}-\frac{a / b-c-h T^{*}}{h}\right)+\frac{(a / b-c)^{4}}{12 h^{2}} .
\end{aligned}
$$

\section{Derivation Process of $T^{* \prime}(h)$ in Section 4.3}

By partially differentiating $h$ with (23), the following formula is obtained (see Appendix B for details):

$$
\begin{aligned}
0= & \left(e T^{* \prime}(h)-2 T^{*} T^{* \prime}(h)\right)\left(\frac{a}{b}-c-h T^{*}\right)^{2} \\
& +T^{*}\left(e-T^{*}\right) \cdot 2\left(\frac{a}{b}-c-h T^{*}\right) \times\left(-h T^{* \prime}(h)\right. \\
& \left.-T^{*}\right)-\left(e-T^{*}\right)\left(\frac{a}{b}-c-h T^{*}\right)^{2} T^{* \prime}(h) \\
& -\int_{0}^{T^{*}}(e-t) \cdot 2\left(\frac{a}{b}-c-h t\right)(-t) d t=T^{* \prime}(h) \\
& \cdot\left[\left(e-2 T^{*}\right)\left(\frac{a}{b}-c-h T^{*}\right)^{2}\right. \\
& -2 h T^{*}\left(e-T^{*}\right)\left(\frac{a}{b}-c-h T^{*}\right)
\end{aligned}
$$

$$
\begin{aligned}
T^{* \prime}(h)= & \frac{-2 \int_{0}^{T^{*}}\left[T^{*}\left(e-T^{*}\right)\left(a / b-c-h T^{*}\right)-t(e-t)(a / b-c-h t)\right] d t}{T^{*}\left(a / b-c-h T^{*}\right)^{2}+2 T^{*}\left(e-T^{*}\right)\left(a / b-c-h T^{*}\right)} \\
= & \frac{-2\left[T^{* 2}\left(e-T^{*}\right)\left(a / b-c-h T^{*}\right)\right]}{T^{*}\left(a / b-c-h T^{*}\right)^{2}+2 T^{*}\left(e-T^{*}\right)\left(a / b-c-h T^{*}\right)} \\
& +\frac{2\left[\left(a / b-c-h T^{*}\right)\left(e T^{* 2} / 2-T^{* 3} / 3\right)-h\left(e T^{* 3} / 6-T^{* 4} / 12\right)\right]}{T^{*}\left(a / b-c-h T^{*}\right)^{2}+2 T^{*}\left(e-T^{*}\right)\left(a / b-c-h T^{*}\right)}>0
\end{aligned}
$$

(verified using Figure 3 and referencing (32) and (33)). 


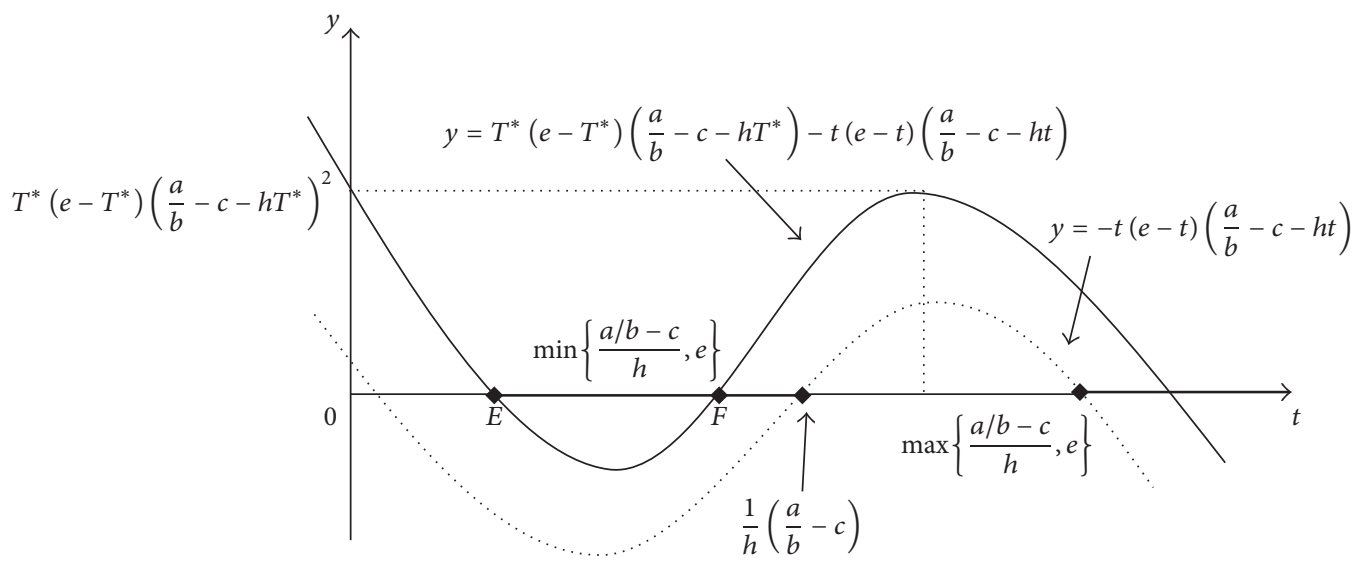

FIgURE 3: Effect of the increase in $h$ on $T^{*}$.

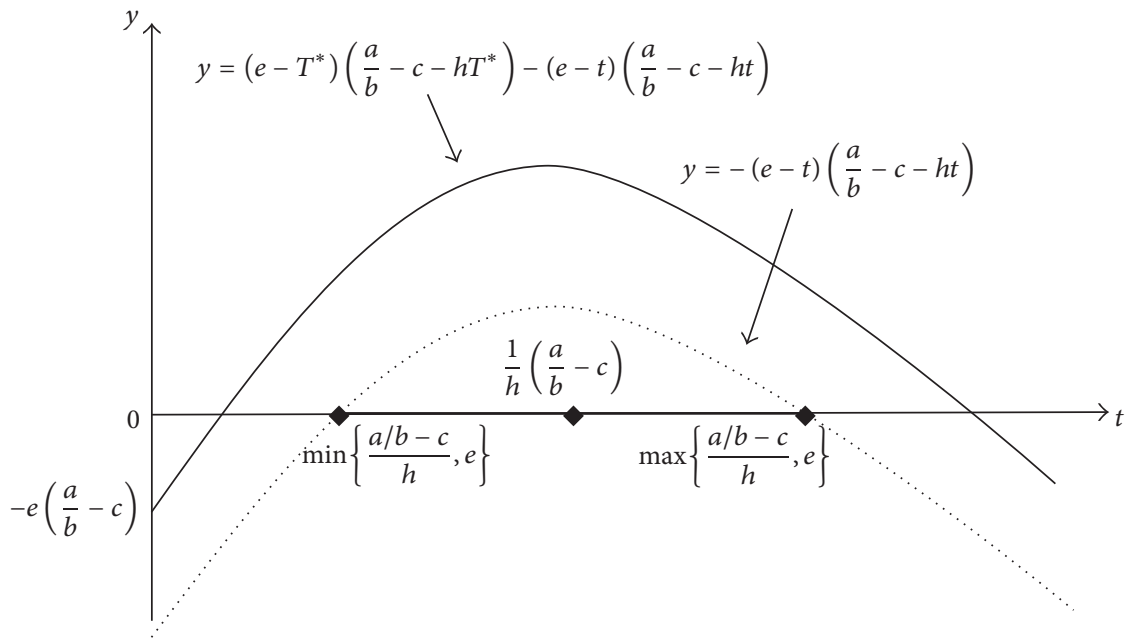

Figure 4: Effect of changes in $c$ on $T^{*}$.

\section{Derivation Process of $T^{* \prime}(c)$ in Section 4.4}

In (23), because $T^{*}$ varies according to $c, T^{*}$ is labeled as $T^{*}(c)$. Partially differentiating $c$ with (23) yields the following formula:

$$
\begin{aligned}
0= & T^{*}\left(e-T^{*}\right) \cdot 2\left(\frac{a}{b}-c-h T^{*}\right)\left(-1-h T^{* \prime}(c)\right) \\
& +\left(e-2 T^{*}\right) \times T^{* \prime}\left(\frac{a}{b}-c-h T^{*}\right)^{2}-\left(e-T^{*}\right)\left(\frac{a}{b}\right. \\
& \left.-c-h T^{*}\right)^{2} \cdot T^{* \prime}(c)+\int_{0}^{T^{*}}\left[( e - t ) \cdot 2 \left(\frac{a}{b}-c\right.\right.
\end{aligned}
$$$$
T^{* \prime}(c)=\frac{-2 \int_{0}^{T^{*}}\left[T^{*}\left(e-T^{*}\right)\left(a / b-c-h T^{*}\right)-(e-t)(a / b-c-h t)\right] d t}{2 h T^{*}\left(e-T^{*}\right)\left(a / b-c-h T^{*}\right)+T^{*}\left(a / b-c-h T^{*}\right)^{2}} .
$$

Thus 


\section{Conflicts of Interest}

The author declares that they have no conflicts of interest.

\section{References}

[1] B. Wierenga, "Model and measurement methodology for the analysis of consumer choice of food products," Journal of Food Quality, vol. 6, no. 2, pp. 119-137, 1983.

[2] J. E. Steenkamp, "Perceived quality of food products and its relationship to consumer preferences: theory and measurement," Journal of Food Quality, vol. 9, no. 6, pp. 373-386, 1987.

[3] C. F. Ross, K. Pecka, and K. Weller, "Effect of storage conditions on the sensory quality of ground arabica coffee," Journal of Food Quality, vol. 29, no. 6, pp. 596-606, 2006.

[4] S. Tarea, G. Cuvelier, and J. M. Sieffermann, "Sensory evaluation of the texture of 49 commercial apple and pear purees," Journal of Food Quality, vol. 30, no. 6, pp. 1121-1131, 2007.

[5] A. Herbon, E. Levner, and T. C. E. Cheng, "Perishable inventory management and dynamic pricing using tti technologies," International Journal of Innovation, Management and Technology, vol. 3, no. 3, pp. 262-266, 2012.

[6] A. Herbon, E. Levner, and T. C. E. Cheng, "Perishable inventory management with dynamic pricing using time-temperature indicators linked to automatic detecting devices," International Journal of Production Economics, vol. 147, pp. 605-613, 2014.

[7] S. Nahmias, "Perishable inventory theory: a review," Operations Research, vol. 30, no. 4, pp. 680-708, 1982.

[8] S. K. Goyala and B. C. Giri, "Recent trends in modeling of deteriorating inventory," European Journal of Operational Research, vol. 134, no. 1, pp. 1-16, 2001.

[9] S. Nahmias, Perishable Inventory Systems, Springer, Boston, MA, USA, 2011.

[10] I. Z. Karaesmen, A. Scheller-Wolf, and B. Deniz, "Managing perishable and aging inventories: Review and future research directions," International Series in Operations Research and Management Science, vol. 151, pp. 393-436, 2011.

[11] M. Bakker, J. Riezebos, and R. H. Teunter, "Review of inventory systems with deterioration since 2001," European Journal of Operational Research, vol. 221, no. 2, pp. 275-284, 2012.

[12] L. Janssen, T. Claus, and J. Sauer, "Literature review of deteriorating inventory models by key topics from 2012 to 2015," International Journal of Production Economics, vol. 182, pp. 86112, 2016.

[13] A. Andijani and M. Al-Dajani, "Analysis of deteriorating inventory/production systems using a linear quadratic regulator," European Journal of Operational Research, vol. 106, no. 1, pp. 8289, 1998.

[14] J.-M. Chen and L.-T. Chen, "Pricing and production lotsize/scheduling with finite capacity for a deteriorating item over a finite horizon," Computers and Operations Research, vol. 32, no. 11, pp. 2801-2819, 2005.

[15] Z. T. Balkhi and L. Tadj, "A generalized economic order quantity model with deteriorating items and time varying demand, deterioration, and costs," International Transactions in Operational Research, vol. 15, no. 4, pp. 509-517, 2008.

[16] H.-J. Chang and P.-Y. Chen, "An EOQ model with controllable selling rate," Asia-Pacific Journal of Operational Research, vol. 25, no. 2, pp. 151-167, 2008.

[17] Y. He, S.-Y. Wang, and K. K. Lai, "An optimal productioninventory model for deteriorating items with multiple-market demand," European Journal of Operational Research, vol. 203, no. 3, pp. 593-600, 2010.

[18] A. A. Alamri, “Theory and methodology on the global optimal solution to a general reverse logistics inventory model for deteriorating items and time-varying rates," Computers and Industrial Engineering, vol. 60, no. 2, pp. 236-247, 2011.

[19] M. Cheng, B. Zhang, and G. Wang, "Optimal policy for deteriorating items with trapezoidal type demand and partial backlogging," Applied Mathematical Modelling. Simulation and Computation for Engineering and Environmental Systems, vol. 35, no. 7, pp. 3552-3560, 2011.

[20] K.-C. Hung, "An inventory model with generalized type demand, deterioration and backorder rates," European Journal of Operational Research, vol. 208, no. 3, pp. 239-242, 2011.

[21] S.-W. Lin, "Inventory models with managerial policy independent of demand," European Journal of Operational Research, vol. 211, no. 3, pp. 520-524, 2011.

[22] K. Gumasta, F. T. S. Chan, and M. K. Tiwari, "An incorporated inventory transport system with two types of customers for multiple perishable goods," International Journal of Production Economics, vol. 139, no. 2, pp. 678-686, 2012.

[23] Y. He and S. Wang, "Analysis of production-inventory system for deteriorating items with demand disruption," International Journal of Production Research, vol. 50, no. 16, pp. 4580-4592, 2012.

[24] S. Agrawal, S. Banerjee, and S. Papachristos, "Inventory model with deteriorating items, ramp-type demand and partially backlogged shortages for a two warehouse system," Applied Mathematical Modelling. Simulation and Computation for Engineering and Environmental Systems, vol. 37, no. 20-21, pp. 89128929,2013

[25] T. Avinadav, A. Herbon, and U. Spiegel, "Optimal inventory policy for a perishable item with demand function sensitive to price and time," International Journal of Production Economics, vol. 144, no. 2, pp. 497-506, 2013.

[26] A. Chauhan and A. P. Singh, "Optimal replenishment and ordering policy for time dependent demand and deterioration with discounted cash flow analysis," International Journal of Mathematics in Operational Research, vol. 6, no. 4, pp. 407-436, 2014.

[27] R. Roy Chowdhury, S. K. Ghosh, and K. S. Chaudhuri, "An inventory model for perishable items with stock and advertisement sensitive demand," International Journal of Management Science and Engineering Management, vol. 9, no. 3, pp. 169-177, 2014.

[28] M. Amirthakodi, V. Radhamani, and B. Sivakumar, "A perishable inventory system with service facility and feedback customers," Annals of Operations Research, vol. 233, pp. 25-55, 2015.

[29] A. K. Bhunia, A. A. Shaikh, G. Sharma, and S. Pareek, "A two storage inventory model for deteriorating items with variable demand and partial backlogging," Journal of Industrial and Production Engineering, vol. 32, no. 4, pp. 263-272, 2015.

[30] D. Dutta and P. Kumar, "A partial backlogging inventory model for deteriorating items with time-varying demand and holding cost," International Journal of Mathematics in Operational Research, vol. 7, no. 3, pp. 281-296, 2015.

[31] K. V. Geetha and R. Udayakumar, "Optimal replenishment policy for deteriorating items with time sensitive demand under trade credit financing," American Journal of Mathematical and Management Sciences, vol. 34, no. 3, pp. 197-212, 2015. 
[32] P. Hu, S. Shum, and M. Yu, "Joint inventory and markdown management for perishable goods with strategic consumer behavior," Operations Research, vol. 64, no. 1, pp. 118-134, 2016.

[33] C.-Y. Dye, H.-J. Chang, and C.-H. Wu, "Purchase-inventory decision models for deteriorating items with a temporary sale price," International Journal of Information and Management Sciences, vol. 18, no. 1, pp. 17-35, 2007.

[34] P. H. Hsu, H. M. Wee, and H. M. Teng, "Preservation technology investment for deteriorating inventory," International Journal of Production Economics, vol. 124, no. 2, pp. 388-394, 2010.

[35] J. C. Yu, "Optimal deteriorating items inventory model with a three-echelon supply chain strategic alliance," Asia-Pacific Journal of Operational Research, vol. 27, no. 6, pp. 693-711, 2010.

[36] Y.-S. Huang, W.-J. Su, and Z.-L. Lin, "A study on lead-time discount coordination for deteriorating products," European Journal of Operational Research, vol. 215, no. 2, pp. 358-366, 2011.

[37] J. Blackburn and G. Scudder, "Supply chain strategies for perishable products: the case of fresh produce," Production and Operations Management, vol. 18, no. 2, pp. 129-137, 2009.

[38] T. Avinadav, A. Herbon, and U. Spiegel, "Optimal ordering and pricing policy for demand functions that are separable into price and inventory age," International Journal of Production Economics, vol. 155, pp. 406-417, 2014.

[39] P.-Y. Chen, M.-S. Chen, and I.-C. Chen, "The optimal price control model of food sales in a given period," Journal of Information and Optimization Sciences, vol. 34, no. 6, pp. 20-31, 2013.

[40] P.-Y. Chen, M.-S. Chen, and C.-Y. Lin, "The inventory model of the effect of product validity on consumer purchase intension," ICIC Express Letters, vol. 7, no. 7, pp. 2115-2120, 2013.

[41] E. Bottani, G. Ferretti, R. Montanari, and M. Rinaldi, "Analysis and optimisation of inventory management policies for perishable food products: A simulation study," International Journal of Simulation and Process Modelling, vol. 9, no. 1-2, pp. 16-32, 2014.

[42] S.-C. Chen and J.-T. Teng, "Retailer's optimal ordering policy for deteriorating items with maximum lifetime under supplier's trade credit financing," Applied Mathematical Modelling. Simulation and Computation for Engineering and Environmental Systems, vol. 38, no. 15-16, pp. 4049-4061, 2014.

[43] S.-C. Chen and J.-T. Teng, "Inventory and credit decisions for time-varying deteriorating items with up-stream and downstream trade credit financing by discounted cash flow analysis," European Journal of Operational Research, vol. 243, no. 2, pp. 566-575, 2015.

[44] O. Boxma, D. Perry, and S. Zacks, "A fluid EOQ model of perishable items with intermittent high and low demand rates," Mathematics of Operations Research, vol. 40, no. 2, pp. 390-402, 2015.

[45] X. Chao, X. Gong, C. Shi, and H. Zhang, "Approximation algorithms for perishable inventory systems," Operations Research, vol. 63, no. 3, pp. 585-601, 2015.

[46] P. Guchhait, M. K. Maiti, and M. Maiti, "An EOQ model of deteriorating item in imprecise environment with dynamic deterioration and credit linked demand," Applied Mathematical Modelling. Simulation and Computation for Engineering and Environmental Systems, vol. 39, no. 21, pp. 6553-6567, 2015.

[47] A. Herbon, "Optimal two-level piecewise-constant price discrimination for a storable perishable product," International Journal of Production Research, 2015.
[48] G. Mahapatra, S. Adak, T. Mandal, and S. Pal, "Inventory model for deteriorating items with time and reliability dependent demand and partial backorder," International Journal of Operational Research, vol. 29, no. 3, p. 344, 2017.

[49] P. L. Abad, "Optimal pricing and lot-sizing under conditions of perishability, finite production and partial backordering and lost sale," European Journal of Operational Research, vol. 144, no. 3, pp. 677-685, 2003.

[50] Y.-C. Tsao and G.-J. Sheen, "Joint pricing and replenishment decisions for deteriorating items with lot-size and timedependent purchasing cost under credit period," International Journal of Systems Science. Principles and Applications of Systems and Integration, vol. 38, no. 7, pp. 549-561, 2007.

[51] C.-T. Chang, J.-T. Teng, and S. K. Goyal, "Inventory lot-size models under trade credits: a review," Asia-Pacific Journal of Operational Research, vol. 25, no. 1, pp. 89-112, 2008.

[52] C.-T. Yang, L.-Y. Ouyang, K.-S. Wu, and H.-F. Yen, "An inventory model with temporary price discount when lead time links to order quantity," Journal of Scientific and Industrial Research, vol. 69, no. 3, pp. 180-187, 2010.

[53] J. Wu, L.-Y. Ouyang, L. E. Cárdenas-Barrón, and S. K. Goyal, "Optimal credit period and lot size for deteriorating items with expiration dates under two-level trade credit financing," European Journal of Operational Research, vol. 237, no. 3, pp. 898-908, 2014.

[54] L. Cheng, C.-S. Tsou, and D.-Y. Yang, "Cost-service tradeoff analysis of reorder-point-lot-size inventory models," Journal of Manufacturing Systems, vol. 37, pp. 217-226, 2015.

[55] J.-T. Teng, L. E. Cárdenas-Barrón, H.-J. Chang, J. Wu, and Y. $\mathrm{Hu}$, "Inventory lot-size policies for deteriorating items with expiration dates and advance payments," Applied Mathematical Modelling. Simulation and Computation for Engineering and Environmental Systems, vol. 40, no. 19-20, pp. 8605-8616, 2016.

[56] F. Z. Sargut and G. GülIşısk, "Dynamic economic lot size model with perishable inventory and capacity constraints," Applied Mathematical Modelling. Simulation and Computation for Engineering and Environmental Systems, vol. 48, pp. 806820, 2017.

[57] P. L. Abad, "Optimal price and order size for a reseller under partial backordering," Computers and Operations Research, vol. 28, no. 1, pp. 53-65, 2001.

[58] M.-S. Chen and M.-C. Chu, "The analysis of optimal control model in matching problem between manufacturing and marketing," European Journal of Operational Research, vol. 150, no. 2, pp. 293-303, 2003.

[59] A. Chande, S. Dhekane, N. Hemachandra, and N. Rangaraj, "Perishable inventory management and dynamic pricing using RFID technology," Sadhana, vol. 30, no. 2-3, pp. 307-316, 2005.

[60] A. Bisi and M. Dada, "Dynamic learning, pricing, and ordering by a censored newsvendor," Naval Research Logistics, vol. 54, no. 4, pp. 448-461, 2007.

[61] Y.-C. Tsao and G.-J. Sheen, "Dynamic pricing, promotion and replenishment policies for a deteriorating item under permissible delay in payments," Computers and Operations Research, vol. 35, no. 11, pp. 3562-3580, 2008.

[62] E. Berk, Ü. Gürler, and G. Yildirim, "On pricing of perishable assets with menu costs," International Journal of Production Economics, vol. 121, no. 2, pp. 678-699, 2009.

[63] E. P. Chew, C. Lee, and R. Liu, "Joint inventory allocation and pricing decisions for perishable products," International Journal of Production Economics, vol. 120, no. 1, pp. 139-150, 2009. 
[64] Y. Akçay, H. P. Natarajan, and S. H. Xu, "Joint dynamic pricing of multiple perishable products under consumer choice," Management Science, vol. 56, no. 8, pp. 1345-1361, 2010.

[65] S. Dasu and C. Tong, "Dynamic pricing when consumers are strategic: analysis of posted and contingent pricing schemes," European Journal of Operational Research, vol. 204, no. 3, pp. 662-671, 2010.

[66] R. Maihami and I. N. Kamalabadi, "Joint pricing and inventory control for non-instantaneous deteriorating items with partial backlogging and time and price dependent demand," International Journal of Production Economics, vol. 136, no. 1, pp. 116122, 2012.

[67] A. Herbon, "Dynamic pricing vs. acquiring information on consumers heterogeneous sensitivity to product freshness," International Journal of Production Research, vol. 52, no. 3, pp. 918-933, 2014.

[68] A. Herbon, "Optimal piecewise-constant price under heterogeneous sensitivity to product freshness," International Journal of Production Research, vol. 54, no. 2, pp. 365-385, 2016.

[69] A. K. Bhunia, A. A. Shaikh, and R. K. Gupta, "A study on twowarehouse partially backlogged deteriorating inventory models under inflation via particle swarm optimisation," International Journal of Systems Science. Principles and Applications of Systems and Integration, vol. 46, no. 6, pp. 1036-1050, 2015.

[70] C.-T. Chang, M.-C. Cheng, and L.-Y. Ouyang, "Optimal pricing and ordering policies for non-instantaneously deteriorating items under order-size-dependent delay in payments," Applied Mathematical Modelling. Simulation and Computation for Engineering and Environmental Systems, vol. 39, no. 2, pp. 747-763, 2015.

[71] J. Zhang, Y. Wang, L. Lu, and W. Tang, "Optimal dynamic pricing and replenishment cycle for non-instantaneous deterioration items with inventory-level-dependent demand," International Journal of Production Economics, vol. 170, pp. 136-145, 2015.

[72] C.-Y. Dye and C.-T. Yang, "Optimal dynamic pricing and preservation technology investment for deteriorating products with reference price effects," Omega, vol. 62, pp. 52-67, 2016.

[73] M. Xue, W. Tang, and J. Zhang, "Optimal dynamic pricing for deteriorating items with reference-price effects," International Journal of Systems Science. Principles and Applications of Systems and Integration, vol. 47, no. 9, pp. 2022-2031, 2016.

[74] D. J. Saunders, "Thirty years of the inverse problem in the calculus of variations," Reports on Mathematical Physics, vol. 66, no. 1, pp. 43-53, 2010. 

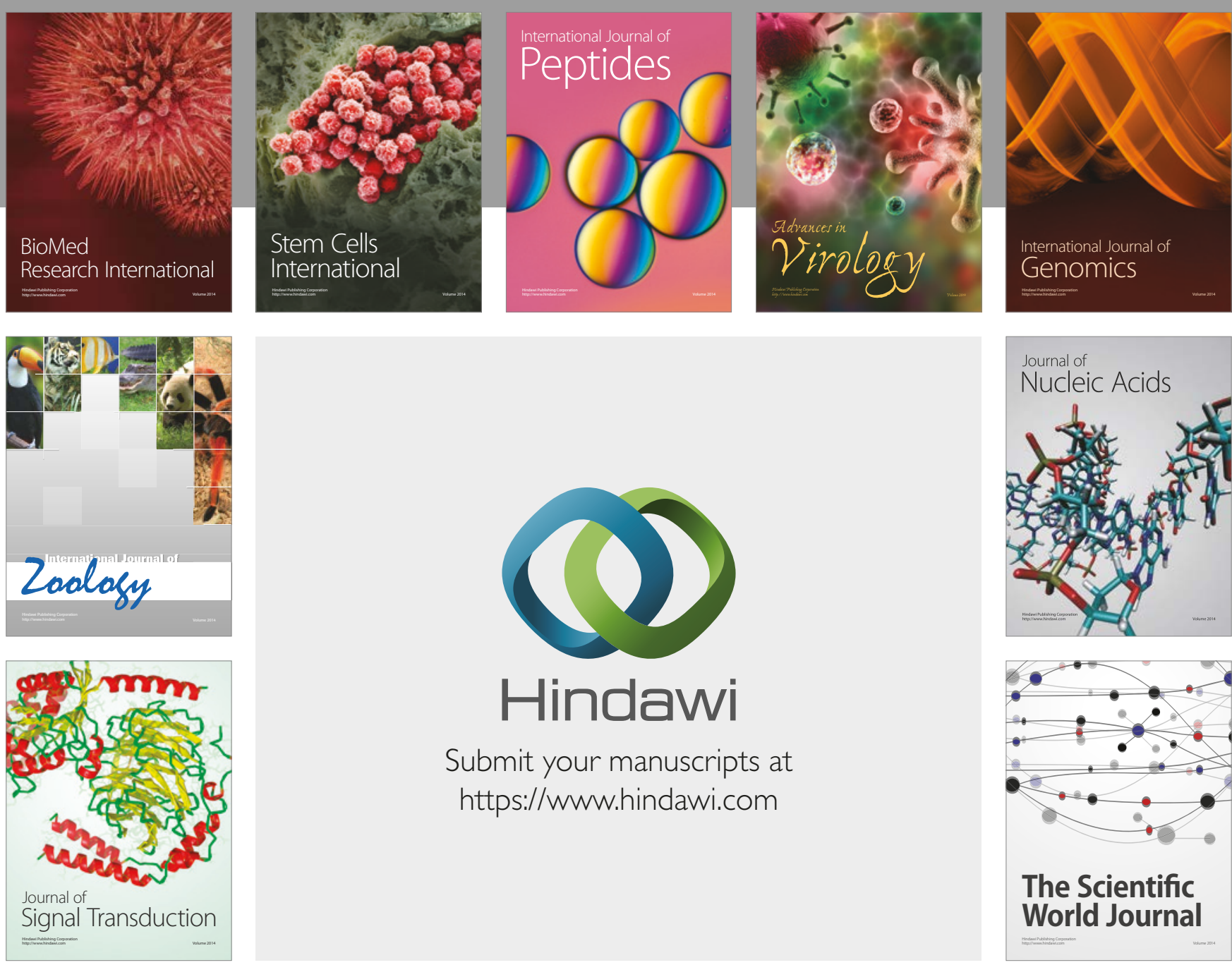

Submit your manuscripts at

https://www.hindawi.com
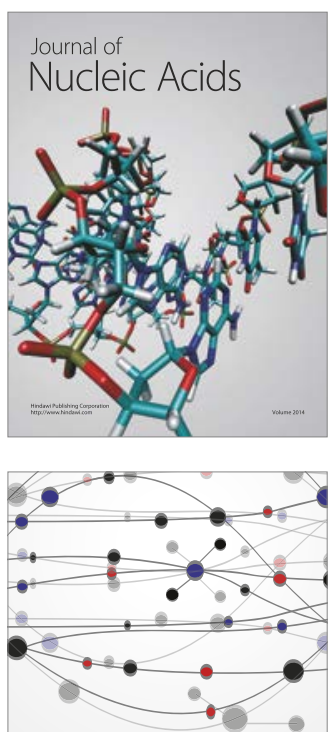

The Scientific World Journal

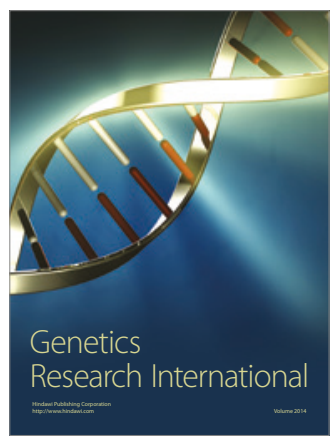

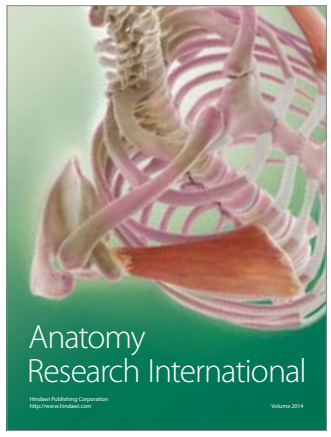

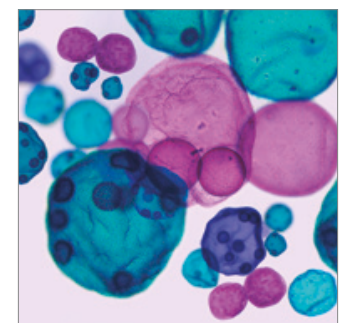

International Journal of Microbiology
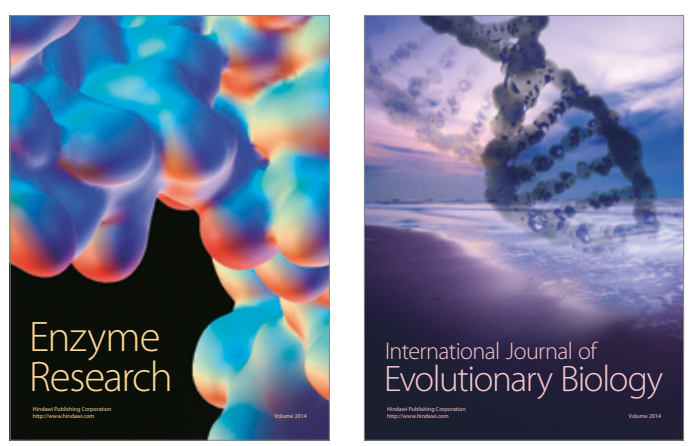
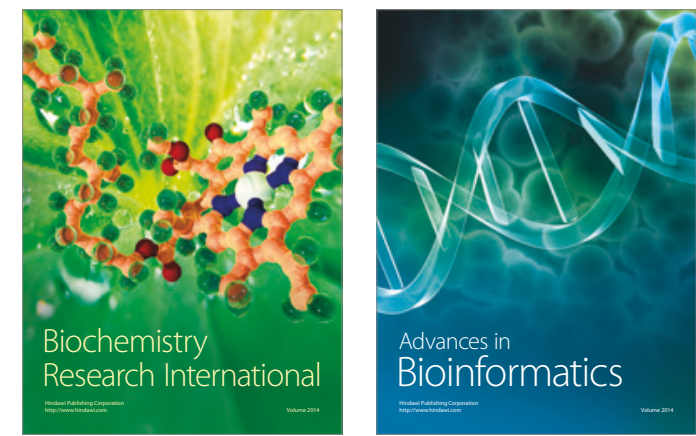

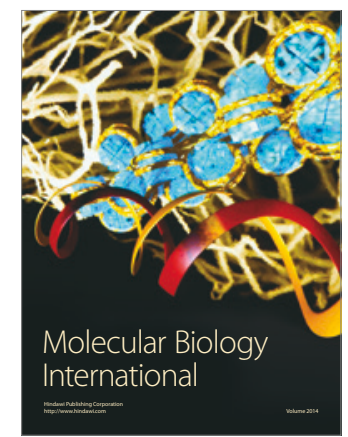

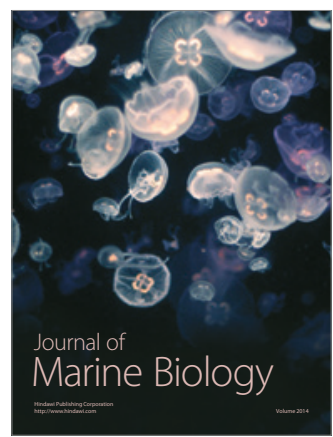

